\title{
A four-year prospective study of the work of the practice nurse in the treatment room of a South Yorkshire practice
}

\author{
W H R WATERS, J M SANDEMAN, J E LUNN
}

\begin{abstract}
Summary and conclusions
During a four-year study period 43985 patients were seen in the treatment room and 61806 coded procedures carried out. Thirty per cent of these procedures were not part of usual nursing curricula and required initial supervision and assessment or training (or both). Nearly $15 \%$ of the patients seen were making a first visit and did not require referral to a doctor. $A$ further $17 \%$ were also making a first visit but were referred to a doctor.

The treatment room made an important contribution to the work of the practice, but this would not have been possible if the staff concerned had been attached nurses requiring area health authority authorisation for procedures carried out as opposed to practice nurses for whom procedures were authorised on a personal basis.
\end{abstract}

\section{Introduction}

The increasing use of health centres has led to considerable discussion over the role of the practice nurse and her training and responsibilities. ${ }^{1-4}$ Recent data ${ }^{5}$ have shown that in England $24 \%$ of practices employed nurses directly and $69 \%$ had attached area health authority nurses. Furthermore, the total hours

\section{Hatfield, Doncaster, S Yorkshire}

W H R WATERS, MBCHB, FRCGP, general practitioner

Hatton, Aberdeenshire

J M SANDEMAN, MBCHB, MRCGP, general practitioner, formerly trainee in Hatfield practice

Sheffield University, Sheffield

J E LUNN, MD, DPH, senior lecturer in community medicine worked by the practice nurses had averaged an $18 \%$ yearly increase since 1968 against an equivalent figure for the attached nurses of only $5 \%$. It appeared that practice nurses worked mainly in surgeries and health centres and attached nurses worked mainly in patients' homes. It was suggested that nurses were employed directly by general practitioners because the existing nursing attachments were ineffective and the attached nurses had created an awareness of the deficiencies.

\section{Background to the study}

Practices in mining areas are known to have higher work loads than average. ${ }^{6} 7$ To work in such areas and attempt to achieve a high standard of patient care necessitates the delegation to adequate nursing and ancillary staff of duties that might otherwise be undertaken by the doctor himself. Consequently there has been a long tradition of nursing duties undertaken by staff employed by the partners and of the delegation of all such work to this staff. The first state-registered nurse was appointed in 1961, but before this appointment and as far back as 1929 the policy of the practice was to employ receptionists with St John Ambulance Brigade nursing certificates.

The study practice has 11400 patients and is based on a health centre in the South Yorkshire coalfield covering four contiguous villages and the surrounding agricultural district.

The original practice premises in a rented semidetached house had a small treatment area, and new purpose built premises in 1960 included a treatment room. In 1974 the practice moved into a new area health authority health centre and before this move plans were made to study the work carried out in the treatment room.

This treatment room has an area of about $27 \mathrm{~m}^{2}$ (290 sq $\mathrm{ft}$ ) and is divided by curtains into two cubicles and a preparation area. Opening from this treatment area is a recovery room $\left(9 \mathrm{~m}^{2}\right.$ (96 sq $\mathrm{ft}$ )) and a test room $\left(5.5 \mathrm{~m}^{2}(60 \mathrm{sq} \mathrm{ft})\right)$. There is a hatch from the test room to a single lavatory reserved for the use of the treatment room.

The treatment areas are staffed by practice nurses from 900 am to $630 \mathrm{pm}$ Monday to Friday and 900 am to 1100 am on Saturday mornings. Four part-time nurses are employed, three of whom have 
been with the practice over 15 years, and one of these has 22 years' general practice experience.

The total nursing time is six hours a week per 1000 patients at risk - that is, 68 hours a week-and, in addition, the attached district nurses now attend for up to two-and-a-half hours a week.

\section{Method}

The name, diagnosis, and treatment (or procedures) carried out on all patients who attended the treatment room between 1 July 1974 and 30 June 1978 inclusive were recorded and coded for analysis. When several procedures were implied in a diagnosis only the main one was coded-for instance, suturing of a wound was recorded as one procedure and not as four (toilet, suture, dressing, and injection of tetanus toxoid). When a patient attended with more than one condition, or when the main procedure did not naturally indicate the others, they were coded separately.

\section{Findings}

During the four-year period 43985 patients were seen in the treatment room by a practice nurse or, on occasions, by an attached nurse, and 61806 coded procedures were carried out (table I). The average of three to four procedures per antenatal or postnatal patient was to some extent an artefact due to counting procedures such as weighing, urine testing, venepunctures, and blood pressure readings separately.

TABLE I-Treatment-room procedures and patients over a period of four years (antenatal and postnatal work and general work)

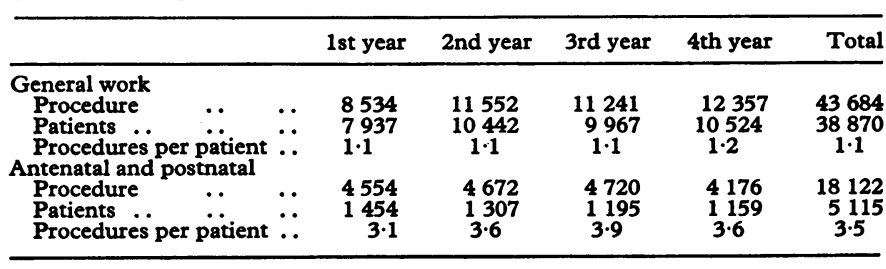

Table II shows the nature of the procedures carried out. The proportion of nursing treatments showed a steady decline over the four years but the proportion of data collection procedures increased fourfold. Indeed, of the 61806 procedures, no less than 24518 $(39.7 \%)$ were concerned with data collection and in respect of the antenatal and postnatal work they accounted for 17212 of the 18122 procedures $(95 \cdot 0 \%)$.

TABLE II-Nature of procedures carried out in treatment room (general work only). (Percentages in parentheses)

\begin{tabular}{|c|c|c|c|c|c|}
\hline & First year & Second year & Third year & Fourth year & All \\
\hline $\begin{array}{l}\text { Nursing } \\
\text { treatments } \\
\text { Data collection } \\
\text { Nursing advice }\end{array}$ & $\begin{array}{r}5642(66 \cdot 1) \\
529(6 \cdot 2) \\
767(9 \cdot 0)\end{array}$ & $\begin{array}{l}7055(61 \cdot 1) \\
1641(14 \cdot 2) \\
1027(8 \cdot 9)\end{array}$ & $\begin{array}{l}6355(56 \cdot 5) \\
2125(18 \cdot 9) \\
1040(9 \cdot 3)\end{array}$ & $\begin{array}{l}6119(49.5) \\
3011(24.4) \\
1221(10.0)\end{array}$ & $\begin{array}{r}25171(57 \cdot 6) \\
7306(16 \cdot 7) \\
4075(9 \cdot 3)\end{array}$ \\
\hline $\begin{array}{l}\text { Specimen } \\
\text { collection }\end{array}$ & $711(8 \cdot 3)$ & $751 \quad(6.5)$ & $699(6 \cdot 2)$ & $1014 \quad(8 \cdot 2)$ & $3175 \quad(7 \cdot 3)$ \\
\hline $\begin{array}{l}\text { doctor } \\
\text { Clerical }\end{array}$ & $\begin{array}{ll}637 & (7 \cdot 5) \\
248 & (2 \cdot 9)\end{array}$ & $\begin{array}{ll}659 & (5 \cdot 7) \\
419 & (3 \cdot 6)\end{array}$ & $\begin{array}{l}576(5 \cdot 1) \\
446(4 \cdot 0)\end{array}$ & $\begin{array}{l}635(5 \cdot 1) \\
337 \quad(2 \cdot 7)\end{array}$ & $\begin{array}{l}2507 \quad(5 \cdot 7) \\
1450 \quad(3 \cdot 3)\end{array}$ \\
\hline All & $8534(100)$ & $11552(100)$ & $11241(100)$ & $12357(100)$ & $43684(100)$ \\
\hline
\end{tabular}

The procedures were also divided into three other categories. Firstly, those that could be expected to be within the competence of any trained nurse-for instance, dressings. Secondly, those where initial assessment of competence was needed both for the sake of the patient and for medicolegal purposes-for instance, ear syringingand, thirdly, those that are not usually part of nursing training so that instruction is necessary-for instance, venepuncture, vitalography, audiometry, and electrocardiography.

About $8 \%$ of procedures required an initial assessment of competence but almost a quarter required preliminary instruction, and the proportion in this third category showed a slow rise during the study (tables III and IV respectively). With varying nursing curricula and individual nurses' differing experience there is no strict dividing line between our second and third categories, but supervision and assessment or training (or both) to achieve a necessary level of competence was necessary for $18854(30.5 \%)$ of the procedures carried out.

TABLE III-Procedures where training or initial supervision was necessary to ensure competence for medicolegal purposes. (Percentages in parentheses)

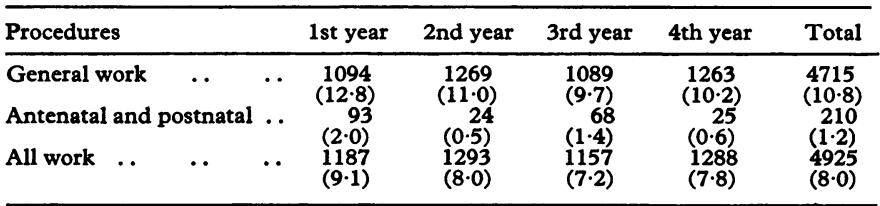

TABLE IV-Procedures where preliminary instruction was required. (Percentages in parentheses)

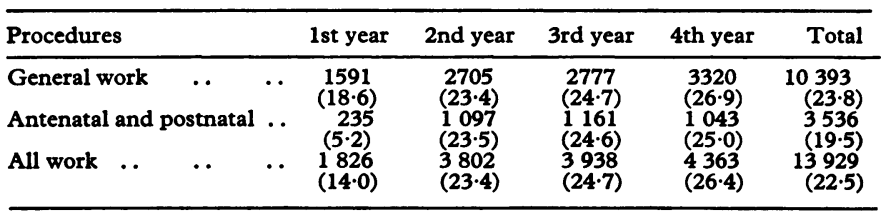

The "work flow" to and from the treatment room was examined (table V). Of the 43985 patients seen in the treatment room, 6455 $(\mathbf{1 4 . 7} \%)$ were seen for the first time by the nurse and did not require referral to a doctor. These patients, under other conditions, would have either used a doctor's time unnecessarily or have done without a consultation altogether. There was a slight tendency for the proportion of such cases to increase over the four years. In a further $7611(17 \cdot 3 \%)$ cases the patients were seen by the nurse on a first visit and were referred to a doctor. The proportion of these cases also tended to increase over the four years. These figures underline Weston Smith and O'Donovan's finding ${ }^{2}$ that the nurse has a definite part to play as the agent of first contact. In 9078 cases $(20.6 \%)$ patients were referred by a doctor in the health centre to the nurse in the treatment room. Once again there was a slight tendency for the proportion of such cases to increase over the years. The remaining attendances were repeat visits.

TABLE V-Workflow to and from the treatment room. (Percentages in parentheses)

\begin{tabular}{|c|c|c|c|c|c|}
\hline & 1st year & 2nd year & 3rd year & 4th year & Total \\
\hline $\begin{array}{l}\text { First visits: patient dealt } \\
\text { with by practice nurse.. } \\
\text { First visits : patient referred } \\
\text { to doctor } \\
\text { Patient passed from doctor } \\
\text { to practice nurse in treat- } \\
\text { ment room }\end{array}$ & $\begin{array}{l}1340 \\
(14 \cdot 3) \\
1519 \\
(16 \cdot 2) \\
1717 \\
(18 \cdot 3)\end{array}$ & $\begin{array}{l}1530 \\
(13 \cdot 0) \\
1861 \\
(15 \cdot 8) \\
2342 \\
(19 \cdot 9)\end{array}$ & $\begin{array}{r}1615 \\
(14.5) \\
1987 \\
(17.8) \\
2261 \\
(20 \cdot 3)\end{array}$ & $\begin{array}{c}1970 \\
(16.9) \\
2244 \\
(19 \cdot 2) \\
2758 \\
(23.6)\end{array}$ & $\begin{array}{c}6455 \\
(14.7) \\
7611 \\
(17.3) \\
9078 \\
(20.6)\end{array}$ \\
\hline
\end{tabular}

\section{Discussion}

A considerable volume of nursing work took place in the treatment room and almost a third of this work concerned procedures requiring initial supervision and assessment or training, or both, to ensure that staff were competent. To a large extent the pattern of work has resulted from the high demand that is known to exist in mining area practices. To some extent also it has resulted from a preference for homebased rather than hospital treatment in the area, a side issue of which has been the development of a domiciliary physiotherapy service by the practice. ${ }^{8}{ }^{9}$ Thus the pattern of teamwork with much delegation of procedure to the nursing staff reflects both the expectations of patients and practice management policy and is in line with the statement by the Chief Medical Officer and the Chief Nursing Officer that "An 
important aim of management within the NHS is to enable the right sort of care to be given in the most efficient and effective way. If efficiency and effectiveness can be improved by extension of the nurses' role in particular ways and if the necessary provisos can be met the merits of such extension should be seriously considered, so long as the ability of the nurses to continue to meet the full nursing needs of the patient is safeguarded."10 This, however, raises a problem in relation to attached nurses because the employing authority is given the task of recognising satisfactory training ${ }^{11}$ and it is difficult if not impossible for an area health authority, working by consensus management through a system of committees, to authorise (or forbid) continually changing sets of procedures in differing general practices to be carried out by a changing population of individual nurses. Not surprisingly therefore a contraction of nursing activities has been reported by Ashworth, ${ }^{12}$ who sees a solution in general practitioners employing their own nurses directly. Presumably the employment trend reported by Reedy et al and referred to earlier ${ }^{5}$ reflects Ashworth's views nationally, and certainly the study practice developed its pattern of treatment-room work over the years using directly employed staff so that the partners took the responsibility and decisions as the employing authority. Some of the additional advantages of such an arrangement included:

(1) Greater opportunity for finding compatible colleagues because making an appointment is a personal matter between the doctors and the nurses.

(2) More professional independence and therefore job satisfaction for the nurse.
(3) Greater continuity of staff within the team.

(4) Hours of work are a matter for local negotiation and can be flexible part time; thus there is the opportunity to employ experienced nurses who are unavailable to area health authorities owing to family commitments and who would, in other circumstances, be unemployed.

\section{References}

${ }^{1}$ Dixon PN. Work of a nurse in a health centre treatment room. $\mathrm{Br} \mathrm{Med} \mathcal{F}$ $1969 ; 4: 292-4$.

${ }^{2}$ Weston Smith J, O'Donovan JR. The practice nurse-a new look. Br Med f 1970;4:673-7.

${ }^{3}$ Hasler JC, Greenland AS, Jacka SM, Pritchard PMM, Reedy BELC. Training for the treatment room sister in general practice. $\mathrm{Br} \mathrm{Med} \mathcal{F}$ $1972 ; 1: 232-4$.

4 Bain DJG, Haines AJ. A treatment room survey in a health centre in a new town. Health Bull $1974 ; 32: 111-19$.

${ }^{5}$ Reedy BLEC, Philips PR, Newell DJ. Nurses and nursing in primary medical care in England. $\mathrm{Br}$ Med 7 1976;2:1304-6.

${ }^{6}$ Rider JG, Waters WHR, Charnock RB, Lunn JE. A study of workload in a mining area practice. $\mathcal{F} R$ Coll Gen Pract 1969;17:361-9.

7 Tudor Hart J. The health of coal mining communities. $\mathcal{F} R$ Coll Gen Pract 1971 ;21:517-8.

${ }^{8}$ Waters WHR, Udy SC, Lunn JE. A domicilliary physiotherapy service. Lancet $1974 ; 1: 1033-4$.

${ }^{9}$ Waters WHR, Udy SC, Lunn JE. Organising a physiotherapy service in general practice. $\mathcal{F} R$ Coll Gen Pract 1975;25:576-84.

10 Yellowlees H, Friend PM. Circular letter CMO (77) 10. CNO (77) 9. $30 / 6 / 77$.

11 Department of Health and Social Security. Health Circular HC (77) 22. June 1977.

12 Ashworth H. Where's nurse? World Med 1979 May 5.

\title{
Hospital Topics
}

\section{“Asset stripping" the declining mental hospital}

\author{
E FOTTRELL，TERRY SPY，GERRI MEARNS， I MACLEAN， MARY FOGARTY
}

\section{Summary and conclusions}

\begin{abstract}
A psychogeriatric day hospital was developed from a long-stay back ward of a large mental hospital whose population of patients had decreased by half. Women in the 70-80 age group with varying degrees of dementia benefited most from such facilities. In view of the current cut-back in Government spending one of the greatest assets in providing a comprehensive service for the elderly mentally infirm may well be found in the declining mental hospital.
\end{abstract}

\section{Introduction}

Psychogeriatric day hospitals are an integral part of a comprehensive service for elderly mentally infirm people maintained

Tooting Bec Hospital, London SW17 8BL

E FOTTRELL, $\mathrm{MB}, \mathrm{BCH}$, consultant psychiatrist

TERRY SPY, RMN, community nursing officer

GERRI MEARNS, BA, social worker

I MACLEAN, SRN, nursing officer

MARY FOGARTY, RMN, sister-in-charge, Beechlawn Day Hospital in the community. Such a unit has been developed in a longstay back ward of a large mental hospital, whose population had decreased by half in 10 years. We discuss the functioning of the unit over two years (1976-8), and the desirability of developing such units in view of the expected increase in the number of elderly mentally infirm patients and the cut-back in Government spending.

\section{Development of the day hospital}

The day hospital was developed in a long-stay back ward of Tooting Bec Hospital in south-west London. The ward chosen was on the ground floor, on the edge of the grounds surrounded by a large green area, and easily accessible to ambulances. The architecture of the ward lent itself admirably to adaptation: the dining area continued as such, the dormitory became a large occupational therapy area, and an annexe functioned as an "aids to daily living" assessment area. Offices and small adjoining rooms functioned as offices for medical and paramedical personnel.

The number of patients on this ward was run down, and the ward was closed for upgrading and decorating, which cost only $£ 29000$ as little structural alteration was necessary. There were few revenue implications and staffing was provided from within the hospital pool. Agreement and co-operation between medical and nursing staff was most important and accelerated development. Administration was 